\title{
HERANÇA DIGITAL: A TRANSMISSÃO DE BENS VIRTUAL
}

\author{
Everton Silva Santos ${ }^{1}$ \\ Tamires Gomes da Silva Castiglioni
}

RESUMO: A Constituição Federal de 1988, em seu art. $5^{\circ}$, inciso XXX, garante a todos o direito à herança. Hoje, o patrimônio do de cujus, é constituído pelo conjunto de bens geridos ao longo de sua vida, que abrange todas as relações jurídicas possíveis, tanto os direitos como os deveres. Com o avanço tecnológico, o ciberespaço tornou-se o meio de comunicação mais utilizado, que liga as pessoas por redes de computadores. De modo que, a herança digital acaba fazendo parte do acervo de bens do falecido, e sendo possível de apropriação por seus herdeiros, nos casos que não houver restrição testamentaria.

Palavras-chave: Herança Digital; Personalidade Após a Morte; Ciberespaço; Bens Virtuais; Tecnologia.

\section{DIGITAL HERITAGE: THE TRANSMISSION OF VIRTUAL OWNERSHIP}

\begin{abstract}
The Federal Constitution of 1988, in its art. 5, item XXX, guarantees everyone the right to inheritance. Today, the assets of the de cujus are made up of the set of assets managed throughout their life, which covers all possible legal relationships, both rights and duties. With technological advancement, cyberspace has become the most widely used means of communication, linking people through computer networks. Thus, the digital inheritance ends up being part of the assets of the deceased, and it is possible to be appropriated by his heirs, in cases where there is no testamentary restriction.
\end{abstract}

Keywords: Digital Inheritance; Personality After Death; Cyberspace; Virtual Possessions; Technology.

\footnotetext{
${ }^{1}$ Mestre em Direito-Universidade Metodista de Piracicaba, UNIMEP (2017). Especialização em Direito do Trabalho e Processual do Trabalho-Centro Universitário Adventista de São Paulo (2016), UNASP. Graduação em Direito pelo Centro Universitário Adventista de São Paulo (2013). Graduação em Ciências Contábeis pelo Centro Universitário Adventista de São Paulo (2009). Atualmente é advogado e Professor Universitário no curso de Direito da Faculdade de Americana-SP. Membro associado do CONPEDI com artigos publicados no Uruguai, Brasil e Portugal. E-mail: everton_santos87@hotmail.com.

${ }_{2}^{2}$ Mestranda em Direito pela Universidade Metodista de Piracicaba, UNIMEP/SP. Tornou-se Bacharel em Ciências Contábeis (2013), pelo Centro Universitário Adventista de São Paulo, Campus Engenheiro Coelho/SP. Graduanda em Direito pelo Centro universitário Adventista de São Paulo, Campus Engenheiro Coelho/SP. Email: tami.ja@ hotmail.com.
} 


\section{INTRODUÇÃO}

Em razão da praticidade, as pessoas estão cada dia mais, transferindo suas vidas para o virtual. A facilidade de acesso, tem propiciado contato continuo com a internet e seus meios. É fato que o Direito não consegue acompanhar o avanço tecnológico, que se modifica em segundos. Hoje, se entende que o patrimônio do falecido, é constituído pelo conjunto de bens geridos ao longo de sua vida, que abrange todas as relações jurídicas possíveis, compreendendo tanto os direitos como os deveres.

A herança é uma garantia constitucional auferido a todos, sendo o conjunto de bens deixados pelo de cujos, que será transmitido aos herdeiros necessários, testamentários, e se houver os legatários. De tal modo, a herança digital é o conjunto de informações acerca de um usuário, que se encontra em rede digital. O ciberespaço é o meio de comunicação feita por redes de computadores através da codificação digital, que possibilita a transmissão de informação, e seu armazenamento, que pode ser feito através de ADrive, Drive, Dropbox, Apple iCloude, Google Drive, entre outros. Assim, assegura que esse espaço virtual conhecido como nuvem "armazena em um computador, o legado de um indivíduo, fazendo parte de sua herança após a sua morte".

Quanto à metodologia, entende-se que, o trabalho se enquadra como bibliográfico e qualitativo, tendo como objetivo apresentar o testamento como mecanismo hábil para a transferência de bens virtuais do falecido, visto que a legislação é esparsa quanto ao assunto. A problemática é: Qual o entendimento atual do ordenamento jurídico sobre a transferência de bens virtuais do de cujos, tendo em vista que o termino de sua personalidade encerra com a morte?

O Código Civil não disciplina a herança digital nos títulos destinados a parte de Sucessão, de modo que acarreta a disparidade das decisões judiciais, visto que os tribunais julgam os casos concretos com base em normas gerais que regulamentam a matéria. Nos casos que o testamento é presente, a transmissão dos bens virtuais é mais simples, visto que nele constará a posição do falecido, quanto a destinação de seu bem. De modo que, quando estes bens estão assegurados em testamento, há a obrigação de transferi-los aos herdeiros.

A Lei $n^{\circ} 12.965$ de 23 de abril de 2014 surgiu para estabelecer princípios, garantias, direitos e deveres para o uso da Internet no Brasil. Nesse sentido, a lei deixa claro, que prevalecerá a vontade do falecido se existir expressão de vontade, não conseguindo os herdeiros pleitear o acesso aos arquivos pessoais. E se inexistir declaração, ficará entendido 
que os bens poderão ser disponibilizados a família. A privacidade do falecido, deve prevalecer acima de tudo, tendo em vista a garantia constitucional à intimidade e vida privada, elencado no art. $5^{\circ}, \mathrm{X}$, da Magna Carta.

Como visto, o tema é divergente, e causa grande insegurança jurídica, visto que os provedores e administradores de serviço de internet, guardam as informações no prazo máximo doze meses, e o processo judicial de inventário para autorização judicial de acesso a informação do falecido, costuma pendurar anos, sendo raramente inferior a um ano. De modo que, os registros não mais existiram após a conclusão judicial.

\section{A HERANÇA DIGITAL}

A Magna Carta, em seu art. $5^{\circ}$, inciso XXX, garante a todos o direito à herança. Sendo o conjunto de bens deixados pelo de cujos, que será transmitido aos herdeiros necessários, testamentários, e se houver os legatários.

A herança digital tem sido um desafio ao Poder Judiciário e ao direito sucessório, frente aos avanços tecnológicos. Segundo Franco (2015, p.51), a discussão acerca da herança digital vem movimentado o judiciário desde meados de 2000. Os estudos existentes são primitivos, e o campo da matéria tem grande potencial de desenvolvimento. De modo que a virtualização tem sido cada dia mais intensa, e a sociedade tem utilizando as redes sociais para armazenar informações pessoais e até mesmo profissionais.

Oliveira (2015, p.24) explica, que a herança digital é o conjunto de informações acerca de um usuário, que se encontra em rede digital. Franco (2015, p.34) conceitua como direito e obrigação de um indivíduo, necessariamente falecido, para seus herdeiros, fronte a lei, e suscetível de apropriação. Hoje, se entende que o patrimônio do de cujus, é constituído pelo conjunto de bens geridos ao longo de sua vida, que abrange todas as relações jurídicas possíveis, compreendendo tanto os direitos como os deveres.

E, exatamente por ter sido construído em vida, o perfil pode, muitas vezes, alcançar o status de relíquia, ser tomado como representação da pessoa que se foi e, em consequência disso, como ferramenta para a manutenção de sua memória. Uma ferramenta que pode, ainda, ser retomada por um parente que a administrará, mantendo, por ai nada mais tempo, a memória daquela pessoa que se foi. (MARTINS, 2013, p.34). 
A herança digital para Cahn e Beyer (2013, p.138) pode ser dividida de quatro formas: dados pessoais; dados de redes sociais; dados de contas financeiras e dados de contas empresariais. Os dados pessoais, temos como exemplo o e-mail, whatsap, e armazenamento de dados. Os dados de redes sociais, são os mais comuns em nossa geração, como o Facebook e Instagram. Dados financeiros são os aplicativos online da conta bancaria e planilhas que apontam o controle dos gastos. E por fim, os dados de contas empresariais, são aquelas voltas a área profissional, como site empresarial, site de vendas, etc.

Os dois meios hábil para que os herdeiros tenham acessam ao acervo digital do falecido, de acordo com Lima (2013, p.32) são:

A primeira, em relação aos arquivos suscetíveis de apreciação econômica. Estes comporão a herança, gerando direitos hereditários; a segunda, em relação aos arquivos insuscetíveis de valoração econômica prevalece a vontade do de cujus: se inexistir expressão de vontade, não poderão os herdeiros pleitear a posse dos arquivos pessoais, mas poderão solicitar a retirada de material publicado ostensivamente; existindo declaração de vontade (expressa ou tácita), respeitar-se-á a manifestação.

\section{O CIBERESPAÇO}

De acordo com Franco (2015, p.19) ciberespaço é o meio de comunicação feita por redes de computadores através da codificação digital, que possibilita a transmissão de informação. Nele existe ainda, empresas virtuais e mecanismos que proporcionam o convívio e a interação social, de modo que a "interconexão é um dos pulsores mais fortes na origem do ciberespaço" (p.20).

O ciberespaço possibilita o serviço de nuvem, que nada mais é do que o armazenamento de dados através de ADrive, Drive, Dropbox, Apple iCloude, Google Drive, entre outros. Assim, Silva (2014, p.31) assegura que esse espaço virtual conhecido como nuvem "armazena em um computador, o legado de um indivíduo, fazendo parte de sua herança após a sua morte".

\footnotetext{
Além de senhas, tudo o que é possível comprar pela internet ou guardar em um espaço virtual, como música e fotos, passa a fazer parte do patrimônio das pessoas e, competentemente, do chamado acervo digital. Os arquivos digitais podem ser bens guardados, tanto na máquina do próprio usuário quanto por meio da internet em servidores com este propósito, conhecido como armazenamento em nuvem. (LIMA, 2013, p.32).
} 
Lima (2016) relata que o armazenamento de informação pessoais, "ciberespaço", tem sido uma prática frequente, visto a consolidação mundial da rede global nas últimas décadas.

\section{OS BENS VIRTUAIS}

Os bens virtuais de acordo com Augusto e Oliveira (2015, p.8) fazem parte cada vez mais, do cotidiano das pessoas, podendo ser objeto de negociação e lazer.

Vários são os entendimentos sobre a liberação dos bens virtuais do falecido a seus herdeiros. Primeiramente Veigas (2015) acerva que os bens virtuais (temos por exemplo as fotos, arquivos e músicas) não geram direito sucessório, por não apresentarem valorização econômica, e sim sentimental. Costa Filho (2016) acrescenta, que os bens virtuais, exclusivamente de valor afetivo, podem um dia se tornar fonte de propriedade intelectual, e assim não seria possível de sucessão. Já Lima (2013) entende que o falecido não gostaria que sua privacidade fosse exposta a família, (como seu e-mail pessoal, fotos e conversas), e de tal modo, não seria correto considerar os bens virtuais a título de herança.

[...] os bens virtuais merecem ser incluídos no conceito de herança, uma vez que
integram o patrimônio do indivíduo. Quanto aos arquivos que possuam valor
econômico, [...], tendo em vista o princípio da patrimonialidade que norteia o direito
das sucessões. Em contrapartida, alguns doutrinadores entendem que os arquivos
que não podem ser avaliados financeiramente, como fotos pessoais, escritos caseiros
e vídeos particulares são excluídos da concepção de espólio. No entanto, os
sucessores podem herdar este material caso haja disposição de última vontade do de
cujus, na hipótese de não existir, os herdeiros não poderão pleitear judicialmente a
posse do referido conteúdo, mas terão o direito de requerer a exclusão desse acervo,
caso esteja disponível ao público em redes sociais, por exemplo. (VIRGÍNIO, 2015).

Quanto aos arquivos insuscetíveis de valoração, Lima (2016, p.58) argui, que na ausência de qualquer manifestação por parte do falecido, é liberado aos herdeiros o acesso e a posse das informações pessoais.

Sobre as posições acima, Franco (2015) ilude que o correto seria a declaração de vontade do falecido, que ao criar o perfil na rede social ou meio eletrônico, optando pela sucessão hereditária ou não, de modo a impedir violações à privacidade. E este seria suprido pelo testamento, caso existisse.

Para Dias (2013, p.352) o testamento é a melhor forma de assegurar a vontade do falecido, pois é resguardado pelo princípio da autonomia da vontade. Podendo o titular 
nomear herdeiros, de seus bens como também legatários. Em relação a inclusão dos bens digitais no testamento, a legislação brasileira não faz restrição alguma, ficando apenas a indagação de quais bens digitais poderiam se enquadrar. Lara $(2016$, p. 92) acerva o rol de bens digitais possíveis de configuração no testamento, que são:

No testamento de bens digitais podemos deixar instruções claras sobre o destino de nossos bens: senhas de acesso aos sites, e-mails e redes sociais; inventário prévio do patrimônio digital, e até mesmo os contatos que os contatos que os sucessores devam realizar para acessar a esse patrimônio, como endereços eletrônicos.

Para Lima (2013, p.8.) “a legislação brasileira não apresenta entrave para a inclusão de bens digitais em testamentos. Quando nada for previamente determinado, o Código Civil prioriza familiares do falecido para definir os herdeiros".

\section{O POSICIONAMENTO DA LEGISLAÇÃO ACERCA DO TEMA}

Segundo Virgínio (2015) o Código Civil não disciplina a herança digital nos títulos destinados a parte de Sucessão, de modo que acarreta a disparidade das decisões judiciais, visto que os tribunais julgam os casos concretos com base em normas gerais que regulamentam a matéria.

De acordo com o Código Civil em seu art. 1.788, in verbis: “art. 1.788 - morrendo a pessoa sem testamento, transmite a herança aos herdeiros legítimos; o mesmo ocorrerá quanto aos bens que não forem compreendidos no testamento [...]". Nesse contexto, a herança referida no artigo enquadraria também a herança digital? Rohrmann (2005, p. 195) relata que o art. 83, I, do Código Civil, ao estender o conceito de bem móvel às energias que tenham valor econômico, estaria abarcando os arquivos digitais de computadores, de modo que o acervo digital é considerado por Costa Filho (2016, p.191) como conjunto de bens móveis suscetíveis de testamento.

No ordenamento jurídico pátrio não há óbice para se permitir a transferência de arquivo digitais como patrimônio, sobretudo quando advindo de relações jurídicas com valor econômico. A possibilidade de se incluir esse conteúdo no acervo hereditário viabiliza, inclusive, que seja transmitido o acervo cultural do falecido aos seus herdeiros, como forma de materializar a continuidade do saber e preservar a identidade de um determinado sujeito dentro do seu contexto social. (AUGUSTO; OLIVEIRA, 2015, p.12). 
É através do testamento (meio hábil) que pode se transmitir os bens digitais, visto que o ordenamento atual, é ausente de legislação pertinente. De modo que, quando estes bens estão assegurados em testamento, há a obrigação de transferi-los aos herdeiros, exceto as plataformas que tragam cláusula proibitiva de transferência. Em contrapartida, Blum (2012) defende que um provedor de serviço eletrônico, não poderia restringir a transferência hereditária de um bem virtual, assim, Mauro Júnior (2012) complementa que os herdeiros devem pleitear ao juiz a disponibilidade do bem virtual caso ele esteva restrito.

A Lei $\mathrm{n}^{\circ} 12.965$ de 23 de abril de 2014, estabeleceu princípios, garantias, direitos e deveres para o uso da Internet no Brasil. Nesse sentido, a lei deixa claro, que prevalecera a vontade do falecido se existir expressão de vontade, não conseguindo os herdeiros pleitear o acesso aos arquivos pessoais. E se inexistir declaração, ficará entendido que os bens poderão ser disponibilizados a família. (LIMA, 2013, p.33). Costa (2016) defende que a privacidade do falecido, deve prevalecer acima de tudo, tendo em vista a garantia constitucional à intimidade e vida privada, elencado no art. $5^{\circ}, \mathrm{X}$, da Magna Carta.

Como visto, o tema é divergente, e causa grande insegurança jurídica, de modo que Passos (2016) relata que os provedores e administradores de serviço de internet, guardam as informações no prazo máximo doze meses, e o processo judicial de inventário para autorização judicial de acesso a informação do falecido, costuma pendurar anos, sendo raramente inferior a um ano. De modo que, os registros não mais existiram após a conclusão judicial.

Ou seja, se a pessoa morre e não deixa expressa sua vontade em testamento ou codicilo dando destino a tais bens, passado um ano e os familiares que queiram ter acesso a eles, não terão como resgatar ou ter acesso, mesmo que haja determinação judicial, já que os servidores têm a obrigação de mantê-los armazenados por apenas um ano. (CORREIA, 2016, p.51).

\section{A PERSONALIDADE APÓS A MORTE}

A personalidade está prevista no Código Civil de 2002, no Capítulo II, do Título I, do Livro I, que determina o término da personalidade com a morte. (NEVES; SÁ, 2009, p.74). Assim, faz-se necessário antes tudo, conceituar a personalidade.

Para Fiuza e Godinho (2009, p. 110), os direitos de personalidade são algo recente, fruto da doutrina francesa de meados do século XIX, de modo que são direitos respectivos à tutela da pessoa humana, e fundamentais a sua dignidade. Tepedino (1999, p. 27), entende que 
a personalidade é o conjunto de características e atributos da pessoa humana, que servem para sua proteção. Já Miranda (2000, p. 216) são direitos irrenunciáveis, inalienáveis, irrestringíveis. Assim, Fiuza e Godinho (2009, p. 110), iludem que a doutrina vem entendendo que os Direitos de Personalidade são extrapatrimoniais, absolutos, imprescritíveis, impenhoráveis e genéricos, por ser direito de todos.

Há que se analisar juridicamente a questão à luz da teoria dos direitos da personalidade, pois o perfil público decorre de uma exteriorização da intimidade do usuário, além do uso de sua imagem, ambos direitos personalíssimos, com todos os atributos que lhe são inerentes (MELLO; VANNUCCI, 2008, p. 02).

Com a morte, finda-se a personalidade jurídica, retirando do falecido a aptidão para ser sujeito de direitos e obrigações, convertendo-se em titular de direitos de personalidade. Mas nada impede, que seus herdeiros pleiteiem por seus direitos.

[...] os direitos da personalidade são vitalícios, extinguindo-se, naturalmente, com a morte do titular, confirmando o seu caráter intransmissível. Falecendo, pois, o titular de um direito da personalidade, não haverá transmissão, extinguindo-se, automaticamente, a relação jurídica personalíssima. Não se esqueça de qualquer forma, que se reconhece, como um direito de personalidade da pessoa viva, a proteção aos valores jurídicos da personalidade. (FARIAS; ROSENVALD, 2012, p. 180).

Duarte (2008) contribui, que a duração da vida coincide com a personalidade jurídica, e quando esta se finda, se extingue consequentemente a sua personalidade. $\mathrm{O}$ art. 12 do Código Civil, protege o corpo, a memória e a imagem do falecido, mas não a sua personalidade, pois com o advento da morte, não mais persistem valores patrimoniais, culturais, etc., sendo tudo transmitido aos herdeiros. Assim, os direitos de personalidade não se estendem após da morte, mais os bens virtuais deixados pelo de cujos, como e-mail, redes sociais, documentos eletrônicos se penduram mesmo com o falecimento.

Antes da era digital, com a morte do indivíduo era aberta a sucessão para a partilha de bens, e cumprimento do testamento, (caso existisse). Atualmente com o advento tecnológico, a situação é muito complexa, visto que os bens deixados pelo de cujos, engloba também os virtuais, que são difíceis de mensurar. Surgindo a indagação, se a personalidade se estenderia tendo em visto que a vida virtual do falecido ficaria "ativa" ainda? Os atos praticados na ceara digital em vida, seus efeitos estendem-se mesmo após a morte. De modo que, as redes sociais exclusivas para uso pessoal, de acordo com Sá, Moureira e Almeida (2013, p.108) não poderiam ser transmitidos a herdeiros, como e-mail, Facebook, exceto os que tornariam 
memorial. Já os de uso econômico, podem ser transferidos aos seus herdeiros, para que eles deem continuidade no negócio, como uma empresa virtual.

\section{CONSIDERAÇÕES FINAIS}

Atualmente, as pessoas têm utilizando o meio eletrônico para armazenado de fotos, dados, e realização de serviços pessoais e profissionais. O avanço tecnológico está se evoluindo de tal modo, que a herança virtual está sendo um desafio ao Poder Judiciário. Os estudos atuais sobre tal entendimento, são ainda primitivos, e o campo da matéria tem grande potencial de desenvolvimento.

Hoje, se entende que o patrimônio do de cujus, é constituído pelo conjunto de bens geridos ao longo de sua vida, que abrange todas as relações jurídicas possíveis, compreendendo tanto os direitos como os deveres. Nesse contexto, a herança virtual faz parte dos bens a ser repartido na herança, tendo como meio hábil de repartição do bem o testamento. O testamento é a melhor forma de assegurar a vontade do falecido, pois é resguardado pelo princípio da autonomia da vontade.

O Código Civil de 2002, não disciplina a herança digital nos títulos destinados a parte de Sucessão, contudo a legislação brasileira não apresenta entrave para a inclusão de bens digitais em testamentos. Entende-se até, que o legislador ao incluir o conceito de bem móvel às energias que tenham valor econômico, estaria abarcando os arquivos digitais de computadores.

Nesse sentido, a lei deixa claro que prevalecera a vontade do falecido se existir expressão de vontade. A privacidade do falecido deve prevalecer acima de tudo, tendo em vista a garantia constitucional à intimidade e vida privada, elencado no art. $5^{\circ}, \mathrm{X}$, da Magna Carta. Quando a vontade do falecido não for previamente determinada, incube aos herdeiros, pleitear judicialmente pelo bem, diante da ausência de vontade.

A personalidade está prevista no Código Civil de 2002, no Capítulo II, do Título I, do Livro I, que determina o término da personalidade com a morte, retirando do falecido a aptidão para ser sujeito de direitos e obrigações, convertendo-se em titular de direitos de personalidade. O Código Civil de 2002, protege o corpo, a memória e a imagem do falecido, mas não a sua personalidade, pois com o advento da morte, não mais persistem valores patrimoniais, culturais, etc., sendo tudo transmitido aos herdeiros. Assim, os direitos de 
personalidade não se estendem após da morte, mais os bens virtuais deixados pelo de cujos, como e-mail, redes sociais, documentos eletrônicos se penduram mesmo com o falecimento.

Antes da era digital, com a morte do indivíduo era aberta a sucessão para a partilha de bens, e cumprimento do testamento, atualmente com o advento tecnológico, a situação é muito complexa, visto que os bens deixados pelo de cujos, engloba também os virtuais, que nem sempre são fáceis de mensurar.

\section{REFERENCIAS}

Augusto, N. C.; OliveirA, R. N. M. de. A possibilidade jurídica de transmissão de bens digitais “causa mortis" em relação aos direitos personalíssimos do "de cujus". In: Congresso Internacional de Direito e contemporaneidade: mídias e direitos da sociedade em rede. 2015, Santa Maria. Anais, Santa Maria, 2015. Disponível em: <http//coral.ufsm.br/congressodireito/anais>. Acesso em: 10 mai. 2018.

BLUM, R. O. O marco civil da internet e a legislação brasileira. Informativo jurídico Consulex. Brasília, Consulex, v. 25, n. 5, p. 3-4, 31 jan. 2012.

CAHN, N.; BEYER, G. W. Digital Planning: The Future of Elder Law. Naela. v. 9, n. 1,2013. Disponível em: <http://scholarship.law.gwu.edu/cgi/viewcontent.cgi? article $=2255 \&$ context $=$ faculty_publications $>$. Acesso em: 10 mai. 2018.

COSTA FILHO, M. A. F. Herança digital: valor patrimonial e sucessão de bens armazenados virtualmente. Revista Jurídica da Seção Judiciária de Pernambuco, n. 09, 2016. Disponível em: < https://revista.jfpe.jus.br/index.php/RJSJPE/article>. Acesso em: 10 mai. 2018.

CORREIA, J. G. Herança Digital: Sucessão de bens digitais na ausência de testamento. Ano, 9, nº 2, p.46-55, abr/set.2016. Revista Juris Rationis, 2016.

DIAS, M. B. Manual das sucessões. 3 ed. São Paulo: Editora Revista dos Tribunais, 2013.

DUARTE, P. A morte e seus efeitos jurídicos. Publicado em 01/06/2008. Disponível em:<http://www.gostodeler.com.br/materia/5420/a_morte_e_efeito.html>. Acesso em: 10 mai. 2018.

FARIAS, C. C. de; ROSENVALD, N. Curso de direito civil. 1 vol, 10. ed. rev., ampl. e atual. Salvador: Juspodivm, 2012.

FIUZA, C.; GODINHO, A. M. (Org.). Curso avançado de direito civil. 2. ed. Rio de Janeiro: Forense, 2009.

FRANCO, E. L. Sucessão nas redes sociais: tutela jurisdicional dos dados on-line do de cujus. 2015. 71 f. Monografia. (Trabalho de Conclusão de Curso de Graduação em Direito) -

Rev. de Direito, Governança e Novas Tecnologias | e-ISSN: 2526-0049 | Porto Alegre | v. 4 | n. 2 | p. 104 - 115 | Jul/Dez. 2018 
Universidade Federal de Santa Catarina, 2015. Disponível em:< https://repositorio.ufsc.br/bitstream/handle/123456789/158933/TCC>. Acesso em: 10 mai. 2018.

LARA, M. F. Herança digital. Livro eletrônico. Porto Alegre: [s.n.], 2016.

LIMA, I. R. Herança digital: direitos sucessórios de bens armazenados virtualmente. 2013, 57 f. Trabalho de Conclusão de Curso (Graduação em Direito), Faculdade de Direito, Universidade de Brasília, Brasília, 2013. Disponível em: 〈http//bdm.unb.br〉. Acesso em: 10 mai. 2018.

LIMA, I. R. Herança Digital: direitos sucessórios de bens armazenados virtualmente. 2013. 57 f. Trabalho de Conclusão de Curso (Graduação em Direito) - Universidade de Brasília (UnB), Brasília, 2013.

LIMA, M. A. M. Herança Digital: Transmissão post mortem de bens armazenados em ambiente virtual. (Trabalho de conclusão de Curso) 97 f. São Luís, 2016.

MARTINS, D. C. O conceito de Direito. Jus Navigandi, Teresina, ano 16, n. 3076, 3 dez. 2011. Disponível em: <http://jus.com.br/artigos/20549>. Acesso em: 10 mai. 2018.

MAURO JÚNIOR, M. R. Inventário Digital: Responsabilidade pela guarda das informações da pessoa falecida e os requisitos para sua divulgação. Comissão de Ciência e Tecnologia da Ordem dos Advogados do Brasil - Seção de São Paulo, 06 nov. 2012. Disponível em: <http://www.oabsp.org.br/comissoes2010/ciencia-tecnologia/>. Acesso em: 10 mai. 2018.

MELLO, J. Projeto de Lei da Câmara No 75, 2012. Disponível em:〈http://www.senado.gov.br/atividade/materia/getPDF>. Acesso em: 10 mai. 2018.

MELLO, R. S. V.; VANNUCCI, F. H. Os dados pessoais em rede social e a morte do sujeito: considerações sobre a extensão da personalidade civil. 01 jun. 2008. Disponível em: <http://www.esamg.org.br/artigo/DADOS_PESSOAIS_EM_REDE>. Acesso em: 10 mai. 2018.

MIRANDA, F. C. P. de. Tratado de direito privado. Atual. Vilson Rodrigues Alves. 2. ed. Campinas: Bookseller, 2000.

NAVES, B. T. O.; SÁ, M. F. P. Dos direitos da personalidade. Revista Manual de biodireito. Belo Horizonte: Del Rey, 2009.

OLIVEIRA, J. G. G. Luto Digital: Plataformas para a Gestão da Herança Digital. 2015. 116 f. Tese (Mestrado Integrado em Engenharia e Gestão de Sistemas de Informação) Escola de Engenharia da Universidade do Minho, Braga, 2015.

ROHRMANN, C. A. Curso de Direito Virtual. Belo Horizonte: Editora Del Rey, 2005.

SÁ, M. de F. F.; MOUREIRA, D. L.; ALMEIDA, R. B. Direito privado. Belo Horizonte: Arraes, 2013.

Rev. de Direito, Governança e Novas Tecnologias | e-ISSN: 2526-0049 | Porto Alegre | v. 4 | n. 2 | p. 104 - 115 | Jul/Dez. 2018 
SILVA, J. F. Herança digital: a importância desta temática para os alunos dos cursos da Faculdade de Informação e Comunicação da Universidade Federal de Goiás. 2014. 83 f. Trabalho de Conclusão de Curso (Graduação em Biblioteconomia) - Universidade Federal de Goiás, Goiânia, 2014.

TEPEDINO, G. A Tutela da Personalidade no Ordenamento Civil-constitucional. Brasileiro. Temas de direito civil. Rio de Janeiro: Renovar, 1999.

VIEGAS, F. O que fazer com os arquivos digitais de uma pessoa que já morreu: depoimento. [28/01/2015]. Brasília: EBC. Entrevista concedida ao Repórter Brasil. Disponível em: <http://www.ebc.com.br/tecnologia/galeria/ videos/oquefazercomarquivosdigitais-de-uma-pessoa-que-ja-morreu>. Acesso em: 10 mai. 2018 .

VIRGÍNIO, M. A. D. A Sucessão do Acervo Digital. Disponível em: <http://idireitofbv.wikidot.com/sucessaodeacervodigital>. Acesso em: 10 mai. 2018. 